American Journal of Biochemistry and Biotechnology 6 (3): 187-194, 2010

ISSN 1553-3468

(C) 2010 Science Publications

\title{
2-Nonenal-Ovulatory Specific Volatiles in Human Saliva throughout Menstrual Cycle by Gas Chromatography and Mass Spectrometry Analysis
}

\author{
${ }^{1,2}$ S. Alagendran, ${ }^{1}$ G. Archunan, ${ }^{1}$ K. Rameshkumar, ${ }^{1}$ B. Kadalmani, \\ ${ }^{2}$ Jorge Arturo de León Rodriguez, ${ }^{2}$ Gabriela Fernandez, \\ ${ }^{2}$ G. Martínez and ${ }^{2}$ Rosalinda Guevara Guzman \\ ${ }^{1}$ Department of Animal Science, Coordinator for Centre of Pheromone Technology, \\ School of Life Sciences, Bharathidasan University, Tiruchirappalli-24, Tamil Nadu, India \\ ${ }^{2}$ Neurosensorial Physiology Laboratory, Department of Physiology, Pharmacology and Biochemistry, \\ Faculty of Medicine, UNAM, Ave. Universidad C.P-04510, México DF
}

\begin{abstract}
Problem statement: The present investigation carry out a pilot study of a novel method to identify the salivary volatiles in different phases of menstrual cycle for the assessment of ovulation detection using gas chromatography and mass spectrophotometer. Approach: The profiles from follicular phase (6-12 days); ovulatory phase (13-14 days) and luteal phase (15-26 days) of menstrual cycle samples were compared to establish any qualitative and quantitative differences that might have potential value in human olfactory communication. Dichloromethane was used as the solvent for extraction of the compounds. Results: Fifteen compounds were identified. They include organic compounds like, acid, aldehyde, amine and alcohol. The most important constituent was 2-nonenal, which usually comprised $75 \%$ or more of the total volatiles observed in ovulatory phase. The concentration of many constituents varied widely. This appeared to be periodically in three cycles for five of the constituents, with a period of a few weeks and with pronounced maxima at the peak of ovulatory period of which only two were common to all the chromatograms. The chemical profile of ovulatory phase saliva was distinguished by the presence of two specific compounds, viz. 2Nonenal, Acetic acid and Acetaldehyde that were not found in the other reproductive phases of saliva sample in women. Apparently these compounds are 2-nonenal, dodecanol, acetic acid and acetaldehyde. One or more of these compounds may have pheromonal activity in human body odor. Conclusion: Differentiation of the volatile patterns among reproductive phases in women may help to find the diagnostic marker for ovulation detection.
\end{abstract}

Key words: volatiles, ovulation, menstrual cycle, GC-MS

\section{INTRODUCTION}

Ovulation detection of the reproductive phase of a woman is an important decisive factor for applying fertility revealing in human, since the occurrence and duration of the fertile period in reproductive age women are strictly related to the time of ovulation. Based on the previous reports and importance of biochemical constituents in the saliva, the present study is aimed to detect a biomarker in the human saliva for predicting ovulation. Recent year's attention has been paid on the biochemical importance of saliva. Hormones used to measure in blood have now been estimated in saliva, though the quantities are comparatively less
(Braat et al., 1998). Hence, saliva is considered as the best non-invasive source for chemical and biochemical study (Freundl et al., 1996).

Saliva is a complex body fluid containing several different electrolytes including salts of sodium, potassium chloride and non-electrolyte components including several proteins, enzymes and immunoglobulins (Alagendran et al., 2007). There has for many years been a need to detect and diagnose the precise time of ovulation in a given female mammal. It can be of great importance, for example, to pinpoint the time of ovulation to insure that fertilization occurs. Alternatively, it may be important for other medical reasons to diagnose ovulation (Huggins and Preti,

Corresponding Author: G. Archunan, Department of Animal Science, Coordinator for Centre of Pheromone Technology, School of Life Sciences, Bharathidasan University, Tiruchirappalli-24, Tamil Nadu, India 
1976). There is a limited understanding of how the body produces the volatile organic compounds present in human odor. Most of the relevant scientific research pertaining to human scent has evaluated the contents of axillary (armpit) and plantar (foot) sweat. Compounds present in both male (Zeng et al., 1991) and female (Zeng et al., 1996) pH-adjusted axillary secretion extracts have been isolated and identified through preparative gas chromatography, analysis by gas chromatography/mass spectrometry (Preti and Leyden, 2010).

Human odor components have been studied through headspace GC-MS for compounds specific to age (Haze et al., 2001). Compound classes such as hydrocarbons, alcohols, acids, ketones and aldehydes were present in human odor. This study also presented 2-nonenal as a compound that is only present in the odor of individuals over 40 year of age. 2-Nonenal, as well as other aldehydes, was produced through oxidative degradation of monosaturated fatty acids, such as palmitoleic acid and vaccenic acid. Human body odor consists of various odor components. Studies examining the volatile components by various methods have detected the presence of alcohols, ketones, aldehydes, esters, ethers, hydrocarbons and other substances in body odor (Bernier et al., 2000). The key components of body odor present in the sweat, the axillary region, or foot has been determined and the mechanisms by which such odors are formed have been examined (Kanda et al., 1990; Zeng et al, 1991). It is well known that the lipids and their derivatives are involved in the olfactory communication. Here we investigated the changes in human saliva during the period of menstrual cycle found a specific component that is characteristic of the salivary volatiles.

Furthermore, the present study revealed that the change of the monosaturated fatty acid composition of skin surface lipids and the increase in the formation of this characteristic odor component.

\section{MATERIALS AND METHODS}

Collection of whole Saliva: Whole and stimulated parotid saliva samples were collected using sweet free chewing gum for saliva secretion and spitting through the use of a custom-made Lashley Cup. As a part of the collection procedure, subjects were required to undergo a full plaque indexing and oral examination (excluding periodontal probing). Only subjects with good oral hygiene were selected for the study. The salivary samples were collected from 50 different female volunteers having normal menstrual cycle during the age of 20-40 years. The samples were collected during (follicular phase (6-12 day); Ovulatory phase (13-14 day); luteal phase (15-26 day) with help of the day of menses. The samples were screened through nylon mesh $(16-120 \mu \mathrm{m})$ at the time of collection and were stored at $-70^{\circ} \mathrm{C}$ for further use (Navazesh and Christensen, 1982).

Out of the twenty subjects, volunteered to contribute their stimulated parotid saliva samples. A drop of lemon juice was applied to the tongue of the subjects at 5-10 min intervals to stimulate parotid saliva secretion. Samples collected were stored at $-70^{\circ} \mathrm{C}$ until further analysis.

Separations of samples: About $1 \mathrm{~mL}$ of saliva was collected from each individual and was isolated in the ratio chloroform and methanol $(2: 1)$ and centrifuged at $10,000 \mathrm{rpm}$ for $10 \mathrm{~min}$. The separated sample was used for extraction of salivary volatiles using Dichloromethane (1:1 ratio). The tubes were tightly closed and kept for $30 \mathrm{~min}$ at $100^{\circ} \mathrm{C}$ in a water bath. About $2 \mathrm{~mL}$ of methylation reagent was added to each tube and kept again in a water bath at $80^{\circ} \mathrm{C}$ for $20 \mathrm{~min}$. The tubes were closed down to the ambient temperature. Extracting solvent $(1.25 \mathrm{~mL})$ was added to each tube, closed tightly and shaken thoroughly for $10 \mathrm{~min}$. About 2/3 of the organic phase (upper layer) containing the fatty acid methyl esters were transferred into screw cap glass vials.

Gas chromatography: The supernatant was filtered through a silica-gel column (60-120 mesh) and concentrated under vacuum (at $30^{\circ} \mathrm{C}$ ) for fractionation and chemical identification by (a) gas chromatographymass spectrometry (GC-MS; QP-5000, Schimadzu, Japan). Two microlitres of extract was injected into the GC-MS system on a $30 \mathrm{~m}$ glass capillary column with a $\phi 1 \mathrm{~m}$ thickness of $0.25 \mathrm{~mm}$ (30 m $60.2 \mathrm{~mm}$ i.d. coated with UCON HB 2000) using the following temperature programme: initial oven temperature of $408^{\circ} \mathrm{C}$ for 4 min, increasing to $250^{\circ} \mathrm{C}$ at $158^{\circ} \mathrm{C} / \mathrm{min}$ and then held at $250^{\circ} \mathrm{C}$ for $10 \mathrm{~min}$. GC-MS was run under computer control at $70 \mathrm{eV}$. Chemical ionization was performed using ammonia as the reagent gas at $95 \mathrm{eV}$. The solvent (dichloromethane) peak was seen at 2.4 min during the GC-MS analysis. (b) From each vial $1 \mu \mathrm{l}$ of the Fatty Acid Methyl Ester (FAME) was injected into the Gas Chromatography (GC) Column (DEGS) using column temperature of $180^{\circ} \mathrm{C}$ and injection port temperature was $200^{\circ} \mathrm{C}$. Flame Ionization Detector (FID) was used as a detector with $230^{\circ} \mathrm{C}$. Nitrogen was used as reagent gas and then used as a sample for the GC-MS analysis (Kumar et al., 2000). 


\section{RESULTS}

The analysis of human saliva using GC shows 15 different volatiles. Some of the volatile compounds such as carbonic acid, 1-methylcyclopentene and diphenylamine were present in follicular phase. Among these 2-Nonenal were found to be in higher concentration in ovulatory phase when compared to other phases. The two volatiles, carbonic acid and 1methyl-cyclo pentane were elevated in preovulatory phase and these volatiles were comparatively less in phase. And also butanoic acid, 2-propenyl ester and ntetradecane were found in both preovulatory and postovulatory phase while exclusively absent in the ovulatory phase (Table 1 ).

The reproductive phase of menstrual cycle was consistently cyclical changes in volatile components like diphenyl amine $(\mathrm{RT}$ value $=6.37)$ and phenol $(\mathrm{RT}$ value $=12.55$ ) are set forth in Fig. $1 \mathrm{c}$ and $1 \mathrm{~g}$ are remarkably high during follicular phase. Indeed, the relatively high concentrations of diphenylamine have been found at follicular and ovulatory phase, that sharp drops in that concentration have been found at the day prior to ovulation and that concentrations returned to higher levels at the time of ovulation. Concentration variations for over the period of one menstrual cycle to other showing steroids hormone dependent. Such compounds may be used in combinations with other indicators, to confirm the particular menstrual phase of a given subject. It is currently believed that the metabolic pathways which lead to the detection of a large dodecanol spike at the time of ovulation are also likely to cause the spiking of other relatively long-chain alcohols having in the range of 10-16 carbon atoms, particularly 11-14 carbon atoms. The concentration change for dodecanol, as indicated in Fig. 1 was remarkable in light of the fact that a sharp 4-fold change in concentration of this compound occurred precisely at the time of ovulation was indicated.

Table 1: Salivary volatiles examined for changes across a menstrual cycle and their nature of compounds, molecular formula/weight

\begin{tabular}{|c|c|c|c|c|c|c|c|}
\hline $\begin{array}{l}\text { Compound } \\
\text { name }\end{array}$ & $\begin{array}{l}\text { Retention } \\
\text { tine }\end{array}$ & $\begin{array}{l}\text { Follicular phase } \\
\text { (15-26 days) }\end{array}$ & $\begin{array}{l}\text { Ovulatory phase } \\
\text { (13-14 days) }\end{array}$ & $\begin{array}{l}\text { Luteal phase } \\
\text { (6-12 days) }\end{array}$ & $\begin{array}{l}\text { Nature of } \\
\text { compound }\end{array}$ & $\begin{array}{l}\text { Molecular } \\
\text { formula }\end{array}$ & $\begin{array}{l}\text { Molecular } \\
\text { weight }\end{array}$ \\
\hline Carbonic acid & 3.38 & ++ & - & - & Carboxylic acid & $\mathrm{H}_{2} \mathrm{CO}_{3}$ & 62.02 \\
\hline Acetic acid & 5.82 & - & ++ & - & Carboxylic acid & $\mathrm{C}_{2} \mathrm{H}_{4} \mathrm{O}_{2}$ & 60.00 \\
\hline Diphenylamine & 6.37 & +++ & + & - & Amine & $\mathrm{C}_{12} \mathrm{H}_{11} \mathrm{~N}$ & 169.24 \\
\hline 2-Nonenal & 8.25 & - & +++ & - & Aldehyde & $\mathrm{C}_{9} \mathrm{H}_{16} \mathrm{O}$ & 140.12 \\
\hline $\begin{array}{l}\text { butanoic acid, } \\
\text { 2-propenyl ester }\end{array}$ & 9.73 & + & - & + & Ester & $\mathrm{C} 7 \mathrm{H}_{2} \mathrm{O}_{2}$ & 164.00 \\
\hline Dodecanol & 10.50 & + & ++ & - & Alcohol & $\mathrm{CH}_{3}\left(\mathrm{CH}_{2}\right)_{11} \mathrm{OH}$ & 186.34 \\
\hline Phenol & 12.55 & + & ++ & - & Alcohol & $\mathrm{C}_{6} \mathrm{H}_{5} \mathrm{OH}$ & 94.11 \\
\hline Acetaldehyde & 14.40 & - & ++ & - & Aldehyde & $\mathrm{CH}_{3} \mathrm{CHO}$ & 44.06 \\
\hline 4-Methyl phenol & 16.11 & - & - & ++ & Alcohol & C9 $\mathrm{H}_{12} \mathrm{O}$ & 136.00 \\
\hline 1-methyl-cyclopentane & 20.03 & ++ & - & - & Alkane & $\mathrm{C}_{6} \mathrm{H}_{12}$ & 84.16 \\
\hline Skatole & 20.87 & + & - & + & Alcohol & $\mathrm{C}_{9} \mathrm{H}_{9} \mathrm{~N}$ & 131.17 \\
\hline pentanoic acid & 23.22 & - & + & ++ & Carboxylic acid & $\mathrm{C} 5 \mathrm{H}_{10} \mathrm{O}_{2}$ & 102.00 \\
\hline n-tetradecane & 23.87 & + & - & + & Alkane & $\mathrm{C}_{14} \mathrm{H}_{30}$ & 198.39 \\
\hline 3-hexanol & 26.02 & + & - & + & Alcohol & $\mathrm{C} 6 \mathrm{H}_{14} \mathrm{O}$ & 102.00 \\
\hline propionic acid & 28.79 & - & - & ++ & Carboxylic acid & C $3 \mathrm{H}_{6} \mathrm{O}_{2}$ & 130.00 \\
\hline
\end{tabular}

+++: Presently high in triplicate analysis; ++: Raise moderately; +: Present; -: Absent

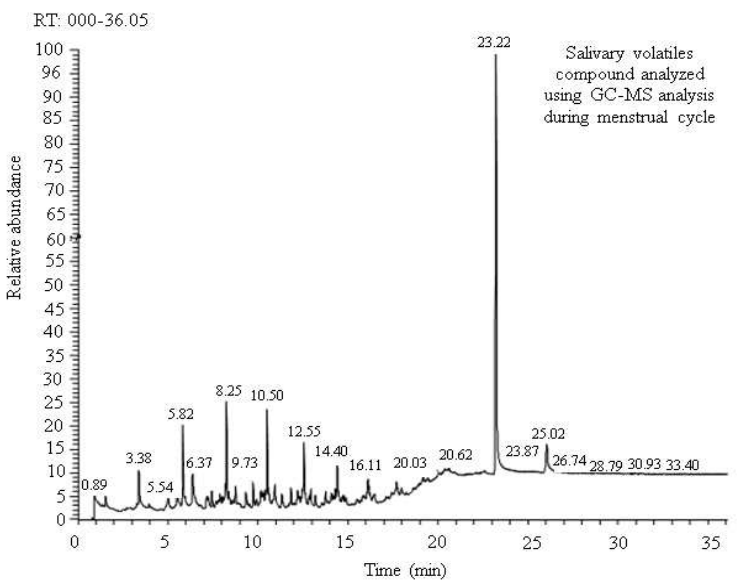

(a)

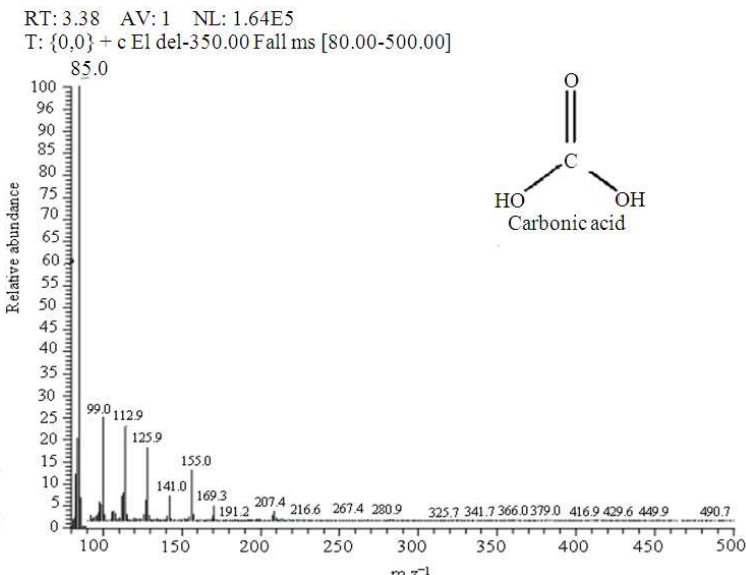

(b) 
Am. J. Biochem. \& Biotech., 6 (3): 188-194, 2010

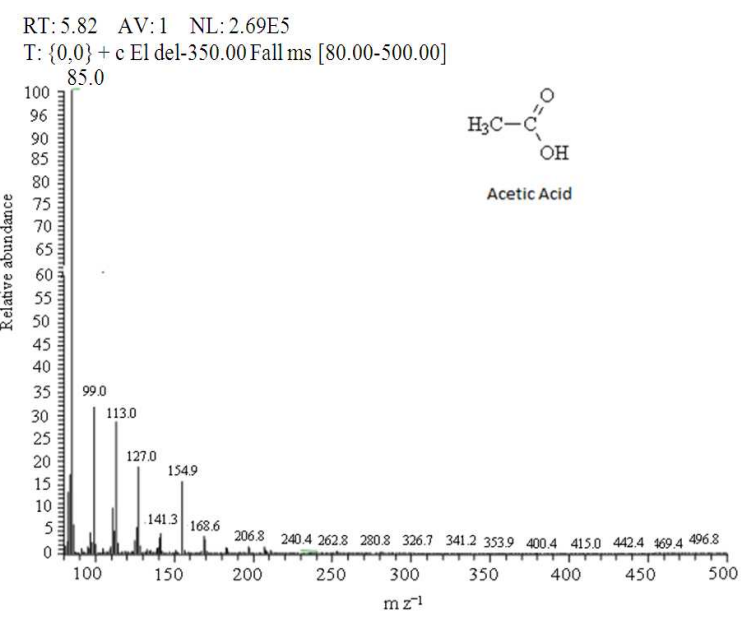

(c)

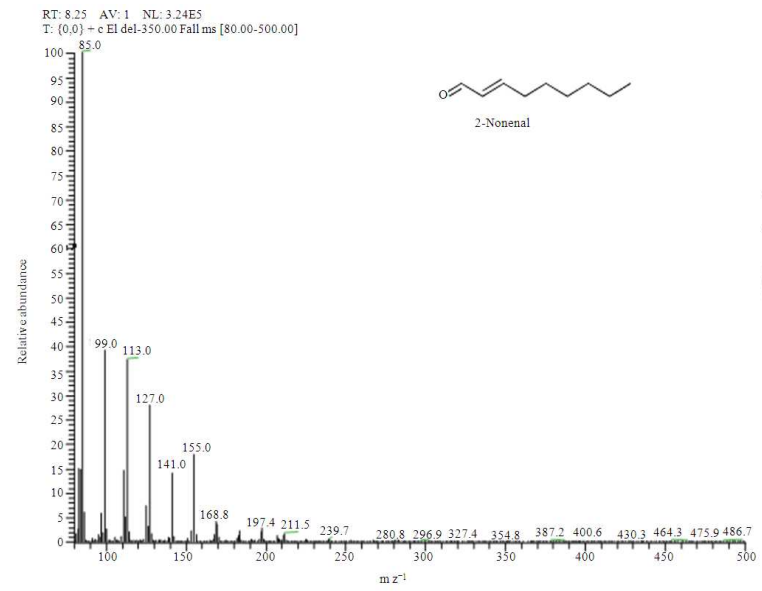

(e)

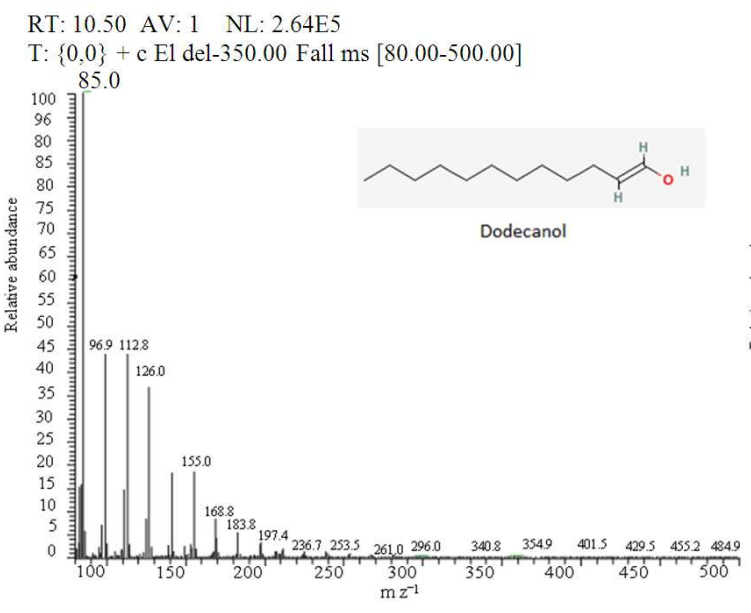

(f)

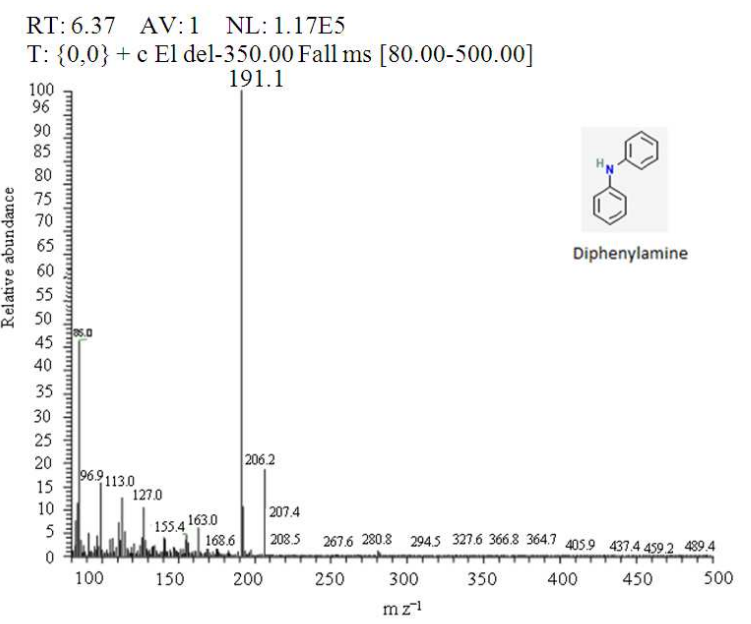

(d)

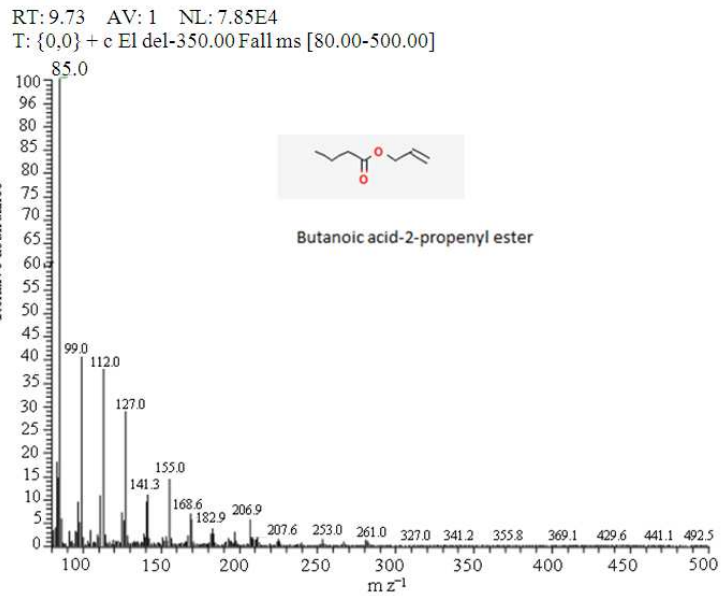

(f)

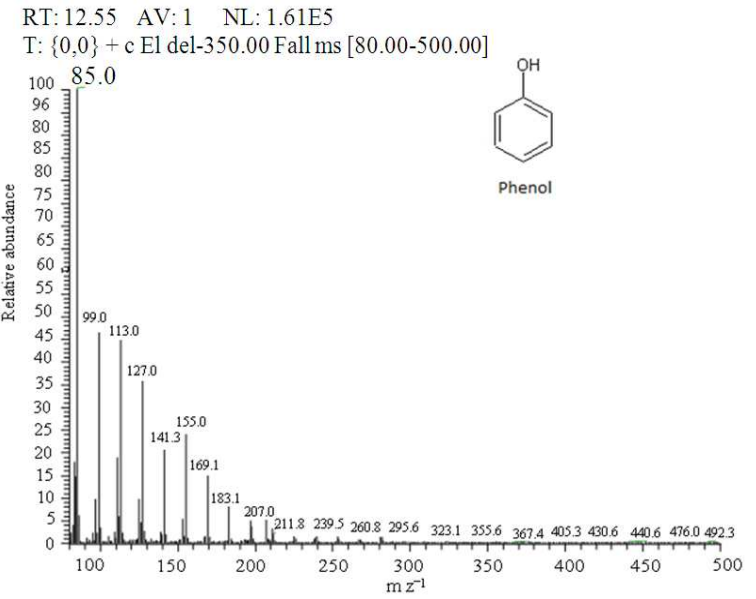

(g) 
Am. J. Biochem. \& Biotech., 6 (3): 188-194, 2010

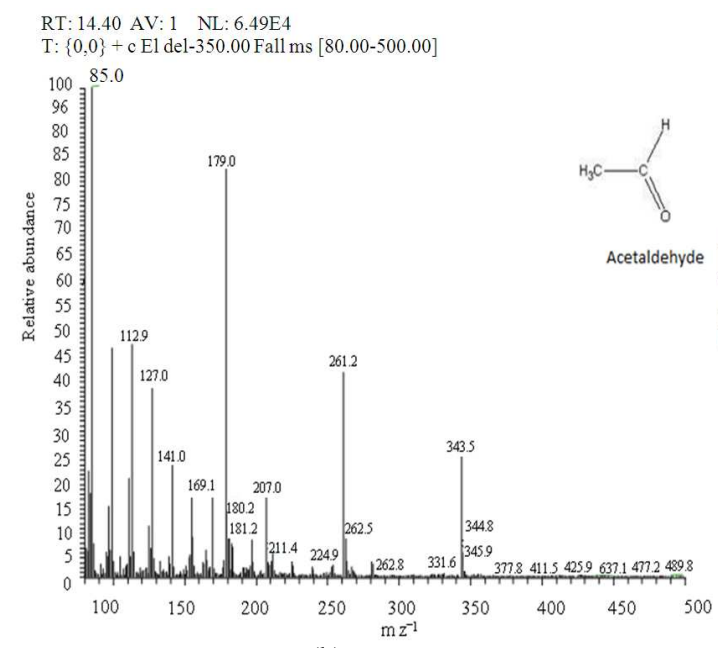

(h)

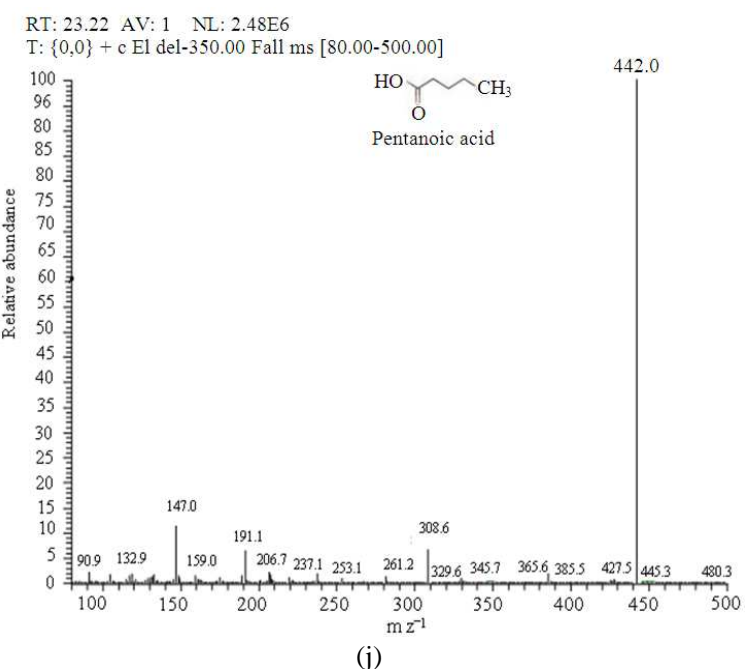

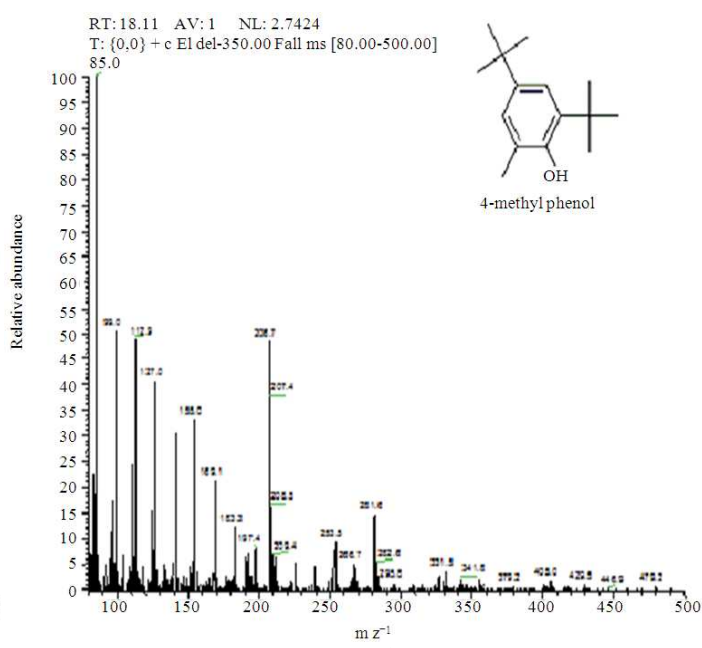

(i)

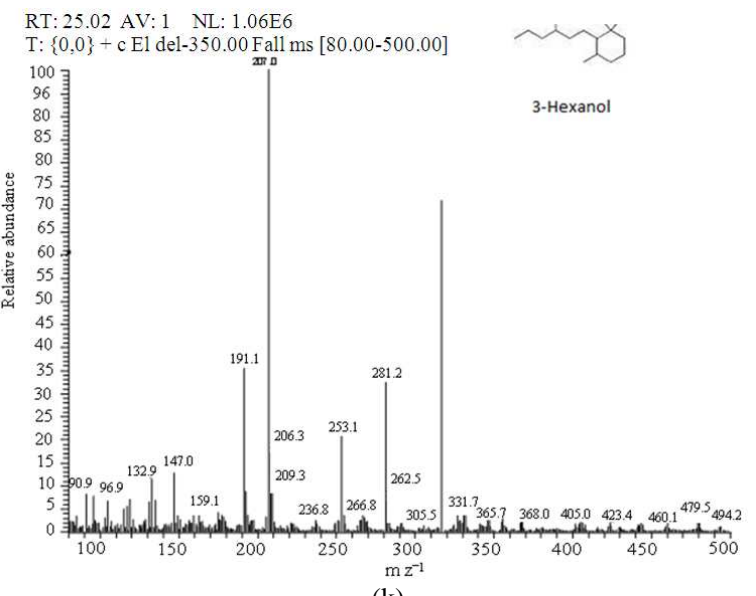

(k)

Fig. 1:The salivary volatiles compound during menstrual cycle

Unlike the other compounds examined in a quantitative manner, this sharp increase at mid-cycle is the only elevation in concentration which was observed for 2nonenal (RT value: 8.25 ), acetic acid (RT value: 5.82 ), acetaldehyde (RT value: 14.40) and dodecanol (RT value: 10.50$)$ are ovulatory specific volatiles in women reproductive periods. Previous report determines that acetaldehyde was the estrus specific volatiles in cow milk (Denhard et al., 1991), urine (Denhard and Claus, 1996; Kumar et al., 2000) and now in saliva was reported as the odor specific volatiles during menstrual cycle.

The data presented for dodecanol is, however, unique and may prove to be superior even to the detection of other compounds which are known to cycle, such as various volatile aldehyde, acidic and alcohol compounds, form a sharp spike in the concentration of such compounds was detected for every subject at the time of ovulation and is believed to occur only once during the entire menstrual cycle (Doty et al., 1975). The reliable method of diagnosing ovulation in a cycling female mammal is disclosed wherein the concentration of 2-nonenal specifically present in human body as odorous substances provide a olfactory signals in human.

\section{DISCUSSION}

The present study was predicated upon the finding that certain long chain alcohols, such as dodecanol, exhibit a unique cyclical behavior during the course of a female's menstrual cycle and accordingly, may be utilized to provide a novel method of diagnosing 
ovulation. By monitoring the concentration of such alcohols, particularly dodecanol, during the menstrual cycle beginning after menses and by providing an indicator means for qualitatively and quantitatively responding to the concentration of such alcohol(s), a method is provided wherein significant increases in the concentration of such aldehydes and alcohol(s) is the biomarker of ovulation (Preti et al., 2009). Generally, the method of the present invention comprises the monitoring of saliva for the concentration of certain long-chain alcohols, particularly those having 10-14 carbon atoms and more particularly dodecanol, by providing an indicator means for qualitatively and quantitatively responding to concentration of said alcohol compounds in saliva, whereby the means for indicating that concentration diagnosis the precise time of ovulation.

Further, the difference in salivary volatiles content across various reproductive phases clearly indicates that these volatiles have got specific role in human olfactory communication depending upon the physiological change of the women reproductive status. The mechanism of fixing volatile molecules by "lipids" has been observed in Tupaia belangeri (Shrew), one of the most primitive mammals (Miyazawa et al., 2008). In certain cases lipids itself act as pheromones. For instance, our previous study also indicated that (Kannan et al., 1998) lipids play a major role in the sexual attraction in Rattus norvegicus. This study focused on the analysis of the GC-MS profiles of the volatile compounds of women saliva in three different phases of follciular, ovulatory and luteal phases has provided evidence that different salivary compounds are present in the different stages. In particular, two peaks present during the ovulatory phase, relating to acetaldehyde and acetic acid, were not found in the other two phases. The appearance of specific peaks in the ovulatory saliva may represent behaviorally important chemical signals. The discovery of substances that appear to be related to ovulation offers a promising approach to this problem. Such substances have been identified in equine urine and reported to act as markers for detection of estrus (Ma and Klemm, 1997). There are also reports that indicate that the oestrus-related odors present in cows' urine can be identified by rats (Denhard and Claus, 1988) and that trained dogs are capable of recognizing characteristic odors in milk during the estrus stage in the cow (Hawk et al., 1984). Furthermore, Weidong et al. (1996) have reported that unique markers for oestrus can be detected in bovine milk. The present findings provide additional support to the possibility of identifying the estrus phase of the cow by detecting urinary pheromonal compounds. Ovulation specific chemical cues might also be useful as sexual stimulants
(Kumar et al., 2000). Both qualitative and quantitative differences were observed among the males and females studied. Various types of compounds were extracted from males and females for odor detection, sinus, axillary, sweat fluids, including a variety of aldehydes, organic fatty acids, ketones and alkanes, which agrees with aging-Haze et al. (2001); sweat(Ostrovskaya et al. 2002), human odor (Martin et al. 2005), human axilla- Wysocki et al. (2009) and nasal fluid Preti and Leyden (2010) analyzed volatile components using GC-MS.

The present study revealed that the salivary volatile compounds such as butanoic acid, skatole and 3hexanol were present in follicular and luteal phases of women reproductive cycle. Among these, 2-nonenal, dodecanol, acetic acid and acetaldehyde are predominantly present in higher concentration in ovulatory phase. Diphenylamine and phenol also present in follciular and ovulatory phase as a chemical stimulants during the period of LH surge. Indeed, it also indicates that the appearances of these volatiles like alcohol, amine and acids in ovulatory and luteal phases are due to the high circulation of steroidal hormones. The difference in the fatty acid composition may be due to the alterations of lipid metabolism especially of metabolic events affecting ketogenesis and would have reflected in the chemical alteration of saliva. The presence of salivary volatiles like 2-nonenal, acetic acid, acetaldehyde and dodecanol with uniform concentration throughout the menstrual cycle showed that these volatiles molecules are influenced by the hormonal changes during menstrual cycle.

Huggins and Preti (1976) support the present investigation which provides a simple, reliable method of detecting ovulation by detecting a single "peak" or "spike" of such alcohol which occurs at the time of ovulation. The aldehyde and alcohol, particularly 2Nonenal and dodecanol, content of saliva, was detected in the gas chromatogram headspace of an incubated sample thereof, is believed to be a secondary characteristic which is responsive to elevated levels of female sex hormones. Unlike other such salivary compounds, dodecanol remains at a relatively constant base level throughout the menstrual cycle, exhibiting a single peak or spike precisely corresponding to ovulation. Unfortunately, the biochemical mechanisms and pathways leading to the production of elevated amounts of dodecanol precisely at the time of ovulation are not currently understood.

Curran et al. (2005) carry out the study as overall, the GC/MS headspace method developed for the analysis of human odor profiles allows for identification of the volatile organic compounds present in human 
scent samples. Through this method, a combination of the relative ratios of common compounds and the presence of differing compounds allows for the chromatographic distinction among individuals. The authors have defined human scent to be the most abundant VOCs present in the headspace above scent samples; however, other substances that have a relatively low volatility or are present in low concentrations may also make contributions to human odor.

\section{CONCLUSION}

The notable amount of 2-nonenal and dodecanol during ovulatory phase in comparison to that of other stages suggests that it may be involved in chemical communication during menstrual periods. Since the ovulatory saliva has the capacity to attract the opposite partner through chemical communication, this volatile present in ovulatory phase appears to play a role in sex conspecifies. Further, the unique correspondence of such dodecanol spikes to the time of ovulation and only to the time of ovulation. The primary object of the present study reveals that the provision of a simple, safe, reliable method of diagnosing ovulation by monitoring the concentration of aldehydes and certain long-chain alcohols in saliva over the course of a given menstrual cycle, a marked increase in the concentration of such aldehydes and particularly 2-nonenal, being diagnostic of ovulation.

\section{ACKNOWLEDGEMENT}

This work was supported by DST-FIST, UGCSAP, India and DGAPA-Becas PAPITT to Dr. SA for postdoctoral research award ship, Mexico has kindly acknowledged.

\section{REFERENCES}

Alagendran, S., G. Archunan and S.S. Achiraman, 2007. Prediction of ovulation in women through the occurrence of salivary fern prototype. IUP J. Life Sci., 1: 7-15.

Curran, A.M., S.I. Rabin, P.A. Prada and K.G. Furton, 2005. Comparison of the volatile organic compounds present in human odor using SPMEGC/MS. J. Chem. Ecol., 31: 1607-1619. PMID: 16222796

Bernier, U.R., D.L. Kline, D.R. Barnard, C.E. Schreck and R.A. Yost, 2000. Analysis of human skin emanations by gas chromatography/mass spectrometry. 2. Identification of volatile compounds that are candidate attractants for the yellow fever mosquito (Aedes aegypti). Anal. Chem., 72: 747-756. PMID: 10701259
Braat, D.D., J.M. Smeenk, A.P. Manger, C.M. Thomas and S. Veersema et al., 1998. Saliva test as ovulation predictor. Lancet, 352: 1283-1284. PMID: 9788464

Denhard, M. and R. Claus, 1988. Reliability criteria of a bioassay using rats trained to detect estrus specific odor in cow urine. Theriogenology, 30: 1127-1138. PMID: 17087902

Denhard, M. and R. Claus, 1996. Attempts to purify and characterize the estrus-signalling pheromone from cow urine. Theriogenology, 46: 13-22. http://www.theriojournal.com/article/0093691X(96)00137-9/abstract

Denhard, M., R. Claus, S. Pfeiffer and D. Schopper, 1991. Variation in estrus-related odors in the cow and its dependency on the ovary. Theriogenology, 35: 645-652.

http://cat.inist.fr/?aModele $=$ afficheN\&cpsidt $=1150$ 0935

Doty, R.L., M. Ford, G. Preti and G.R. Huggins, 1975. Changes in the intensity and pleasantness of human vaginal odors during the menstrual cycle. Science, 190: 1316-1318. DOI: 10.1126/science. 1239080

Freundl, G., M. Bremme, P. Frank-Herrmann, S. Baur and E. Godehardt et al., 1996. The CUE fertility Monitor compared to ultrasound and LH peak measurements for fertile time ovulation detection. Adv. Contracept., 12: 111-121. DOI: 10.1007/BF01849632

Hawk, H.W., H.H. Conley and C.A. Kiddy, 1984. Estrus-related odors in milk detected by trained dogs. J. Dairy Sci., 67: 392-397. DOI: 10.3168/jds.s0022-0302(84)81314-4

Haze, S., Y. Gozu, S. Nakamura, K. Sawano and H. Ohta et al., 2001. 2-Nonenal newly found in human body odor tends to increase with aging. J. Invest. Dermatol., 116: 520-524. DOI: 10.1046/j.0022-202x.2001.01287.x

Huggins, G.R. and G. Preti, 1976. Volatile constituents of human vaginal secretions. Am. J. Obstet. Gynecol., 126: 129-136. PMID: 961738

Kanda, F., E. Yagi, M. Fukuda, K. Nakajima and T. Ohta et al., 1990. Elucidation of chemical compounds responsible for foot malodour. Br. J. Dermatol., 122:771-776. DOI: 10.1111\%2Fj.13652133.1990.tb06265.x

Kannan, S., K.R. Kumar and G. Archunan, 1998. Sex attractants in male preputial gland: Chemical identification and their role in reproductive behavior in rats. Curr. Sci., 74: 689-691.

Kumar, R.K., G. Archunan, R. Jeyaraman and S. Narasimhan, 2000. Chemical characterization of bovine urine with special reference to oestrus. Vet. Res. Commun., 24: 445-454. PMID: 11085464 
Ma, W. and W.R. Klemm, 1997. Variations of equine urinary volatile compounds during the oestrous cycle. Vet. Res. Commun., 21: 437-446. DOI: 10.1023/A:1005859419574

Martin, Y., G. Preti, C.R. Crabtree, T. Runyan and A.A. Vainius et al., 2005. Preference for human body odors is influenced by gender and sexual orientation. Psychol. Sci., 16: 694-701. DOI: 10.1111/j.1467-9280.2005.01598.x

Miyazawa, T., M. Gallagher, G. Preti and P.M. Wise, 2008. The impact of subthreshold carboxylic acids on the odor intensity of suprathreshold flavor compounds. Chem. Percep., 1: 163-167. DOI: 10.1007/s12078-008-9019-z

Navazesh, M. and C.M. Christensen, 1982. A comparison of whole mouth resting and stimulated salivary measurement procedures. J. Dent. Res., 61: 1158-1162.

DOI: $10.1177 / 00220345820610100901$

Ostrovskaya, A., P.A. Landa, M. Sokolinsky, A.D. Rosalia and D. Maes, 2002. The study and identification of volatile compounds from human skin. J. Cosmet. Sci., 53: 147-148.

Preti, G. and J.J. Leyden, 2010. Genetic influences on human body odor: From genes to the axillae. J. Invest. Dermatol., 130: 344-346. DOI: 10.1038/jid.2009.396
Preti, G., E. Thaler, C.W. Hanson, M. Troy and J. Eades et al., 2009. Volatile compounds characteristic of sinus-related bacteria and infected sinus mucus: Analysis by solid-phase microextraction and gas chromatography-mass spectrometry. J. Chromatogr. B: Anal. Technol. Biomed. Life Sci., 877: 2011-2018. PMID: 19553163

Weidong, M.A., B.A. Clement and W.R. Klemm, 1996. Volatile compounds of bovine milk as related to the stage of the estrous cycle. J. Dairy Sci., 80: 3227-3233. PMID: 9436103

Wysocki, C.J., J. Louie, J.J. Leyden, D. Blank and M. Gill et al. 2009. Cross-adaptation of a model human stress-related odor with fragrance chemicals and ethyl esters of axillary odorants: genderspecific effects. Flavor Frag. J., 24: 209-218. DOI: 10.1002/ffj.1927

Zeng, X.N., J.J. Leyden, A.I. Spielman and G. Preti, 1996. Analysis of characteristic human female axillary odors: Qualitative comparison to males. J. Chem. Ecol., 22: 237-257. DOI: 10.1007/BF02055096

Zeng, X.N., J.J. Leyden, H.J., Lawley, K. Sawano and I. Nohara et al., 1991. Analysis of characteristic odors from human male axillae. J. Chem. Ecol., 17: 1469-1492. DOI: 10.1007/BF00983777 